\title{
Erratum: Early ERP signature of hearing impairment in visual rhyme judgment
}

\section{Elisabet Classon*}

Linnaeus Centre HEAD, The Swedish Institute for Disability Research, Department of Behavioural Sciences and Learning, Linköping University, Linköping, Sweden

${ }^{*}$ Correspondence: elisabet.classon@liu.se

\section{Edited by:}

Mari Tervaniemi, University of Helsinki, Finland

Keywords: event-related potentials, hearing impairment, phonology, visual rhyme judgment, inter-stimulus interval, N2, N400, FP

\section{A commentary on}

Early ERP signature of hearing impairment in visual rhyme judgment

by Classon, E., Rudner, M., Johansson, M., and Rönnberg, J. (2013). Front. Psychol. 4:241. doi: 10.3389/fpsyg.2013.00241

This General Commentary provides a corrected version of Figure 6 , page 10. The topographical map of the group with hearing impairment in the $100-300 \mathrm{~ms}$ time-window and $\mathrm{R}-\mathrm{O}-$ condition has been corrected. Figure 6 shows the topographical distribution of the grand averaged ERPs in the normal hearing $(\mathrm{NH})$ and hearing-impaired $(\mathrm{HI})$ groups in the 100-300, 300-500, and 500-700 ms time-windows, long ISI. The rows show the distribution over the $\mathrm{R}+\mathrm{O}+, \quad \mathrm{R}+\mathrm{O}-, \quad \mathrm{R}-\mathrm{O}+$, and $\mathrm{R}-\mathrm{O}-$ rhyme task conditions.

Received: 31 October 2013; accepted: 13 November 2013; published online: 28 November 2013
Citation: Classon E (2013) Erratum: Early ERP signature of hearing impairment in visual rhyme judgment. Front. Psychol. 4:897. doi: 10.3389/fpsyg.2013.00897

This article was submitted to Auditory Cognitive Neuroscience, a section of the journal Frontiers in Psychology.

Copyright (c) 2013 Classon. This is an open-access article distributed under the terms of the Creative Commons Attribution License (CC BY). The use, distribution or reproduction in other forums is permitted, provided the original author(s) or licensor are credited and that the original publication in this journal is cited, in accordance with accepted academic practice. No use, distribution or reproduction is permitted which does not comply with these terms.

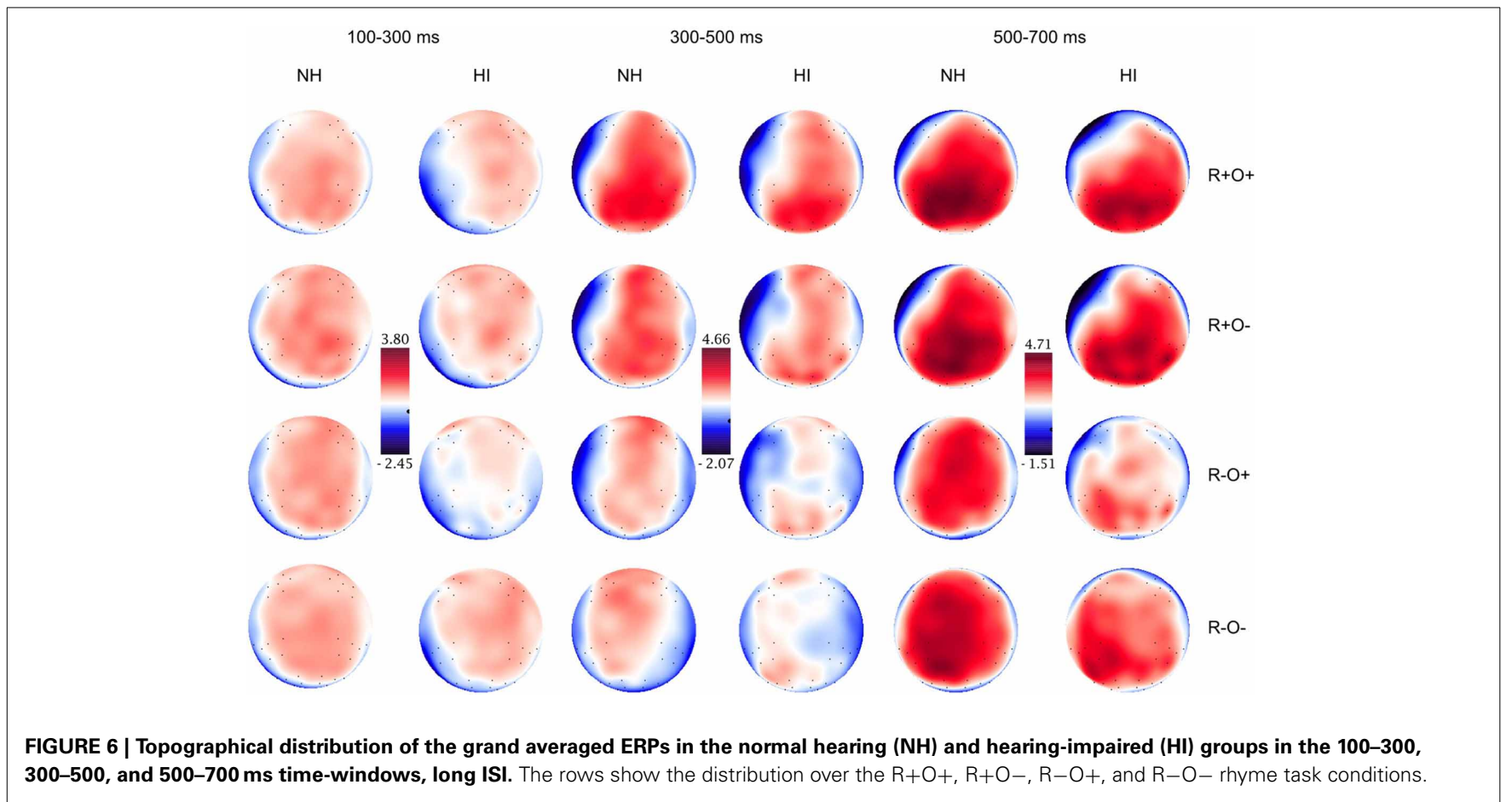

